\title{
My Journey in Academia as a Lipid Biochemist
}

\author{
Viswanathan Natarajan (1) ${ }^{1}$
}

Accepted: 18 May 2021 / Published online: 31 May 2021

(C) The Author(s), under exclusive licence to Springer Science+Business Media, LLC, part of Springer Nature 2021

\begin{abstract}
An overview of Prof. Viswanathan Natarajan's journey in academia as a mentor, teacher, and lipid scientist for nearly 50 years is presented. As a graduate student, Dr. Natarajan interrogated biosynthesis and catabolism of phospholipids in the developing brain; however, in the last five decades, he has been investigating the role of sphingolipids and sphingolipidmetabolizing enzymes in pulmonary endothelial cells, epithelial cells, and fibroblasts under normal conditions and during various lung pathologies such as sepsis, asthma, pulmonary hypertension, idiopathic pulmonary fibrosis, bronchopulmonary dysplasia, and lung cancer. His recent work on sphingosine-1-phosphate and lysophosphatidic acid metabolism in preclinical animal models has identified small molecule inhibitors in the signaling pathways that could have therapeutic potential in ameliorating pulmonary fibrosis, hypoxia-induced pulmonary hypertension, lung cancer, and bronchopulmonary dysplasia. Future research in bioactive lipids in combination with OMICS should unravel the importance of various lipid mediators as modulators of cell function under normal and pathological conditions.
\end{abstract}

Keywords Lipid Biochemist $\cdot$ Academic Journey $\cdot$ Evolution of a Chemist

Although I have spent half of my life in research, I am still learning and there is lots more to research and unravel nature's secrets. Here, I would like to share some of my stories and experiences of my journey as a lipid biochemist in academia.

I was born in Chidambaram, a city famous for the Shiva temple of Lord Nataraja, in the Southern State of Tamil Nadu, India. As a post-independence child belonging to a middle-class Brahmin family, I grew up in Bombay (now Mumbai) and was fortunate to go to good schools and college that my parents could afford. My parents, Vijayavalli and Viswanathan, worked very hard and sacrificed their comforts to get me and my siblings educated, as my father strongly believed that education was the ticket to a

Viswanathan Natarajan

visnatar@uic.edu

1 Departments of Pharmacology \& Regenerative Medicine and Medicine, University of Illinois, Chicago, IL 60612, USA successful career.

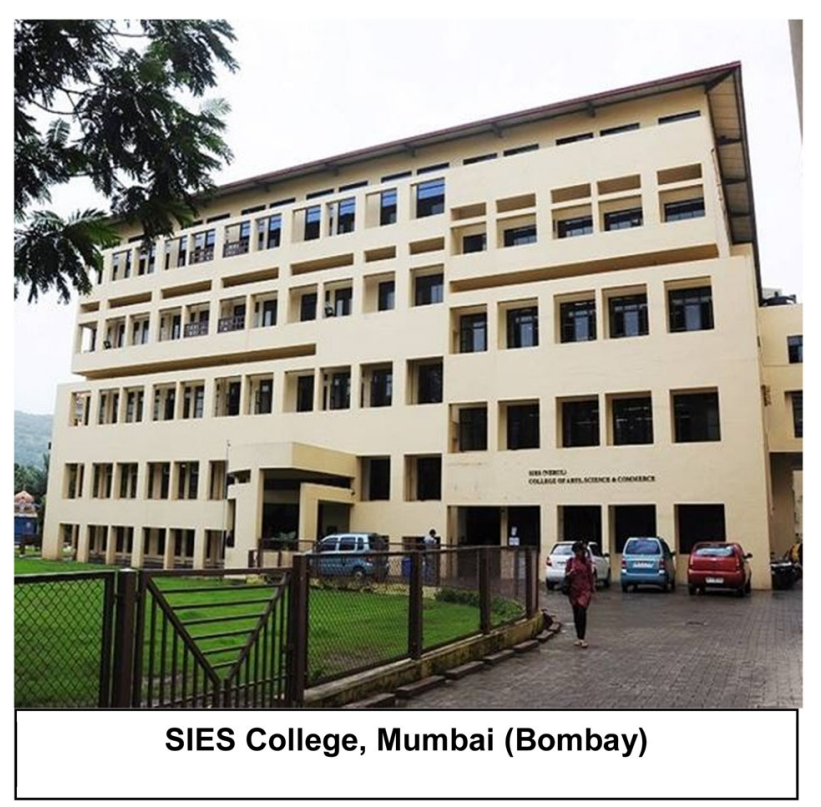

From the time I was in high school, I liked Science, especially chemistry compared to languages and history. Therefore, I opted to select Chemistry as my major in college and Physics as my minor after two years of intermediate. 
Organic chemistry was my favorite and I had two brilliant teachers, Drs. Gogte (Head of Chemistry) and Subramanian at the South Indian Education Society College (SIES), Bombay, India who had exceptional communication skills. My favorite class was organic chemistry, and I enjoyed chemistry labs, especially identification of organic compounds by systematic analysis. The final exams were hard, and competition was extremely high, and getting a First Class (Grade A or higher score) was how anyone earned one of the very limited seats into a Master's or engineering program. I was very nervous until the announcement of the results in the News Papers; however, was relieved to see that I passed with Distinction and Honors. My family was elated at the outcome, and a letter arrived from my College Principal stating that I was a recipient of National Merit Scholarship to pursue higher education. This was the pivotal moment in my life that perhaps directed my career to higher education.

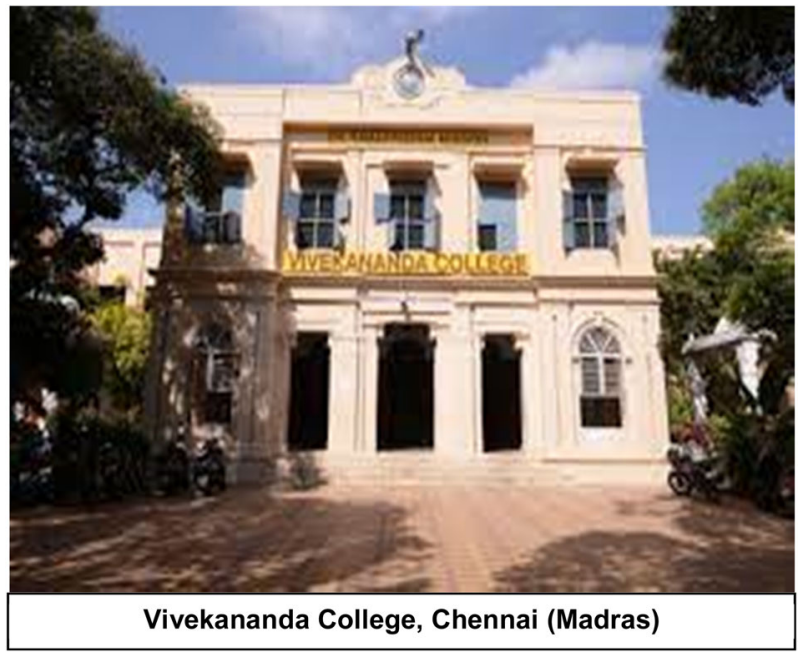

It was a miracle to get admission into Master of Science (M.Sc.) Program in the Chemistry Department of Vivekananda College, Madras (now Chennai). In 1966 when I was doing my undergraduate studies, my father, a central government (Government of India) employee, was transferred from Bombay to Madras, and my parents wanted me to continue my M.Sc. in Madras due to family and financial reasons. Having studied in Bombay, I had no contacts or ideas about colleges and the M.Sc. Chemistry program in Madras. Luckily, a family friend of ours, Dr. K. Vaidyanathan, a Chemistry Professor in Vivekananda College in Madras came to my rescue in providing details on the colleges and admission criteria. The metropolitan city of Madras, with a population of close to 7-8 million, had five colleges affiliated to the Madras University, offering a 2 year M.Sc. Chemistry program; however, each college could admit only 15 students each academic year. The Vivekananda College, an elite educational institution governed by the "Ramakrishna Mission", was highly prestigious and highly rated among the five post-graduate colleges of Madras. Dr. Vaidyanathan was instrumental in arranging an interview with Dr. N. Venkatasubramanian (Dr. NVS), Professor and Head of the Chemistry Department of the Vivekananda college. My one-on-one meeting with Prof. NVS was very productive, and I was very impressed by his approach, kindness, and putting me at ease during the entire process. He took extraordinary steps to recommend me as one the top candidates for the program to the Vice-Chancellor of the University of Madras. Without Prof. NVS, I would not have got into the post-graduate program at the University of Madras, and my career would have taken a different course. I am deeply indebted to Prof. NVS for his kindness, recognition of my talents, and providing me exceptional mentorship not only during my postgraduate training but throughout my academic career.

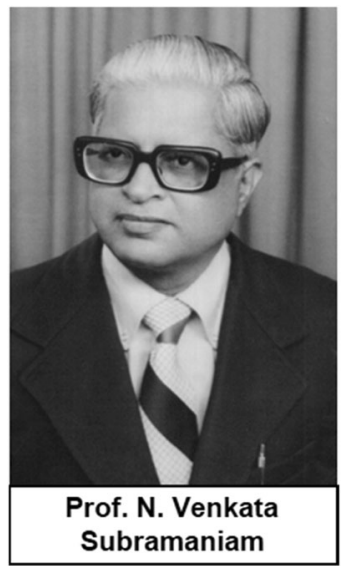

Vivekananda College provided my initial exposure into the fascinating world of Biochemistry and Lipids. Prof. NVS was the first one to seed the concept of "Biochemistry" in the infantile stage of my scientific career. As part of the curriculum, each student was supposed to give an hour lecture on a topic related to organic, inorganic, or physical chemistry. I sought the advice of Prof. NVS and he suggested "Natarajan, can you give a lecture on Cholesterol Biosynthesis in Cells". At that time, we were learning in Organic Chemistry class the various steps involved in the chemical synthesis of cholesterol; however, the term biosynthesis was totally new and not taught to us as chemistry students. I had no option but to go to the British Council Library in the City of Madras to read/study the terminology and concept of biosynthesis and specifically how cells biosynthesize cholesterol. For the first time in my life, I checked out several biochemistry books. Soon, it dawned on me that biochemistry is a huge discipline. Only a few universities in India offered the M.Sc. program (in biochemistry) at that time. I spent the next 3-4 weeks reading the library books, and somehow, managed to put together a lecture on the "Cholesterol 
Biosynthesis" and even today I am not sure if I made any sense to my classmates and faculty. Until this time, I was totally ignorant about the relationship between "Chemistry" and "Biology" and how enzymes in cells catalyze the biosynthesis of macromolecules, thus efficiently mimicking the organic reactions in a test tube. This was an eye opener and I am grateful to Prof. NVS for initiating me into the new world of "Biochemistry" and my first exposure to a lipid molecule of physiological and pathophysiological relevance and significance.

The two-year M.Sc. program ended in April 1970. I thoroughly enjoyed these two years of learning the three branches of chemistry with organic chemistry still being my favorite. Our written exams and labs were evaluated by the external examiners from other universities outside the state of Tamil Nadu and Prof. NVS was extremely pleased and happy that I got a First Class (A Grade) in the program. He immediately appointed me as a Demonstrator in the department with the idea of I join the graduate program in the department. My parents were delighted that I landed on a job and also had the opportunity to do a $\mathrm{PhD}$ under the guidance of Prof. NVS after his return from the US on a sabbatical leave. I was equally thrilled and very thankful to Prof. NVS for being a well-wisher and to take care of my career. At the same time, in his absence, I was thinking about biochemistry and what opportunities were available for me to pursue a graduate program.

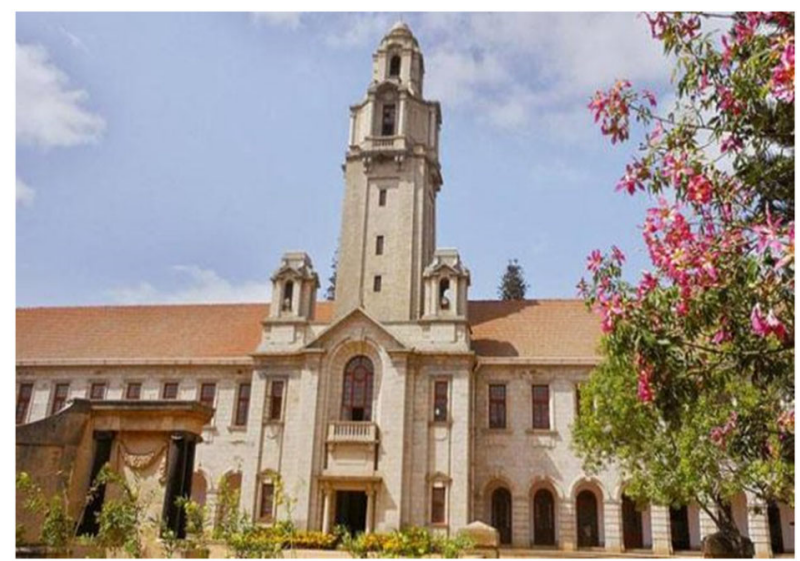

Indian Institute of Sciences (IISc, Bangalore, India)

In 1970, only a few schools in India had a wellestablished graduate program in Biochemistry and one that attracted me the most was the program at the Indian Institute of Science (IISc) in Bangalore, India. The Institute was started in 1909 and the Department of Biochemistry in India was established at the IISc in 1921. The department was a University Grants Commission Center for Advanced Studies and an internationally recognized department for research and training in biochemistry. I took the entrance examination, got through the initial screening, and was called for interview and got selected to the program. All this happened in a short time and I resigned my job at Vivekananda College with a saddened heart and guilty feeling for leaving my mentor, Prof. NVS while he was in USA on a sabbatical.

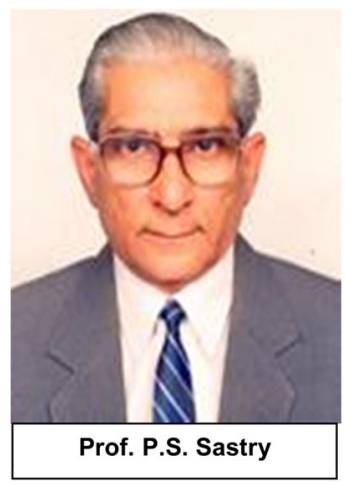

The Head of the Biochemistry department of the IISc in 1970 was Prof. P.S. Sarma, a well-recognized biochemist with international reputation. I was assigned to a Protein lab headed by Prof. Vidyathil; however, this area did not interest me, and I was given the option to join a lipid lab headed by Prof. P.S. Sastry. Prof. Sastry had joined the department as a faculty in 1966 after having trained in the laboratories of Dr. Morris Kates in Ottawa, Canada and Dr. Lowell Hokin of the University of Wisconsin, Madison, Wisconsin. I was happy to be in lipid laboratory, and it was a dream-come-true. A great mentor, Dr. Sastry taught me all about lipids, lipid extraction and separation by the thin-layer (TLC), paper, and gas chromatography (GC) techniques. My doctoral research project was on the "Biosynthesis of Ethanolamine Plasmalogens in the Developing Rat Brain". Being a vegetarian, initially it was difficult for me to sacrifice rat pups for my research work but over a period of six months, I got used to the procedures. Subsequently, I spent five years at the IISc, Bangalore to finish my Ph.D., which were the best times of my academic career. I was mentored by an excellent lipid biochemist and had wonderful friends (most of them are in USA) and the environment at the institute was superb for graduate studies.

My doctoral research work on "Plasmalogen Biosynthesis" was one of the hot topics in the 70's and I was directly competing with the leading research groups of Drs. Amiya Hajra of the University of Michigan, Ann Arbor, Michigan and Fred Snyder of the Oak Ridge National Laboratories, Tennessee. At that time, for our research at the IISc, we had to import most of the fine chemicals and biochemicals from UK and USA, and the waiting period to receive these chemicals were anywhere between three to six months. All experiments must be planned well ahead of time and there was very little room for any mistakes. My doctoral dissertation was evaluated by Drs. Rex Dawson and Greg B 
Ansell in UK, who complimented my research work that led to five publications in the peer reviewed journals [1-3].

I am extremely fortunate for my graduate training and receiving the doctoral degree from the Biochemistry Department of the IISc, Bangalore, India with special homage to my mentor, late Prof. P.S. Sastry, who died in 2016. As a graduate student at the IISc, I had the opportunity to meet and get to know many famous biochemists and lipid biologists who had left an everlasting impression in my life. One such scientist and lipid biochemist is Dr. Dave Brindley, currently Professor at University of Alberta, Canada. While I was a graduate student of biochemistry, Dr. Brindley was a visiting professor of department under British Council Program in 1973, and at that time, he was young Assistant Professor at the University of Nottingham, UK. Dave shared valuable insights into the issues concerning my doctoral research project. He was a good mentor and our friendship and interactions continued after he moved to Canada. Dave is one of the leading scientists in areas of lipids and breast cancer in the world and we continue to interact in the disciplines of mutual interest.
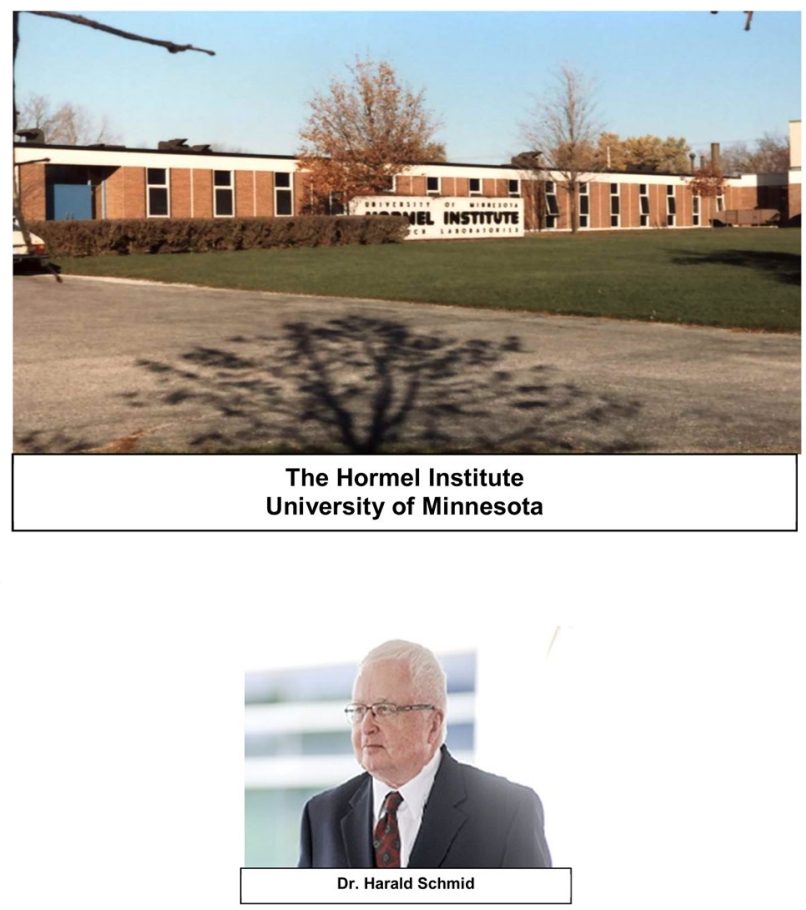

Jobs opportunities for a biochemist in 1970s in India were dismal and most of the Ph.D. graduates ended up in UK, Europe, and USA as post-doctoral fellows. I was not an exception to this tradition at the IISc, and started applying for a post-doctoral fellowship in the USA. In consultation with my mentor, Prof. P.S. Sastry, I applied to several research laboratories in the USA for a post-doctoral position and received an immediate positive response from
Dr. Harald Schmid at the Hormel Institute, a Graduate School of University of Minnesota in Austin, MN. Later, I have received offers from the Johns Hopkins University and Baylor College of Medicine, these mails were delayed, while, as fate would have it, the offer letter from Harald Schmid, came first. At that time, Dr. Schmid's laboratory at the Hormel Institute was investigating the "Metabolism of Ether Lipids" that was close to my Ph.D. research work on the ethanolamine plasmalogens in rat brain, and I decided to accept this offer. I talked to my parents about going to the USA for post-doctoral training; my mother was not enthusiastic and preferred me seeking a job in India and close to Madras. Eventually I was able to convince her and with the nod from the parents accepted the offer. My flight from Chennai was mistakenly booked to Austin, Texas; luckily the error was caught a few days before the departure and flights were rebooked to Rochester, MN as Austin had only a municipal airport.

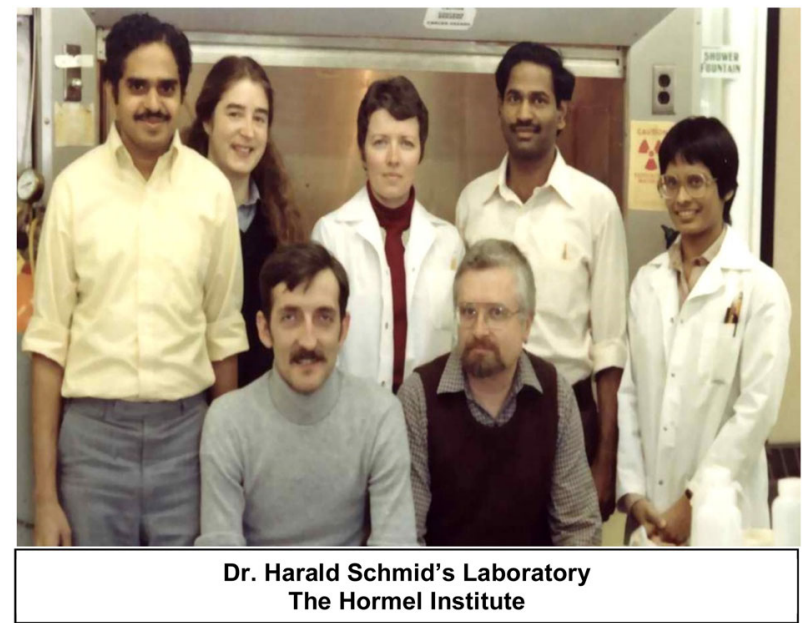

I arrived on November 7th, 1975 and was received by Dr. Schmid at the airport. It was already below zero in MN and I was told that this was just the beginning of the winter. Coming from a tropical country, I had never seen the ground covered with frozen snow which was picturesque. Harald's lab members were cordial, very helpful, and took care of my needs. I had a well-rounded training in several areas of lipid metabolism and biochemistry during my tenure in Harald's laboratory at the Hormel Institute, which was known as the "Mecca for Lipids". Harald and I have become very close family friends and have wonderful memories of our life in Austin and great times with my mentor Harald and his wife Pat and friends at the Institute and the town. I especially thank Patricia Schmid and Dan Selivonchick for their support and care. Dan Selivonchick, a co-post-doctoral fellow in Harald's lab in 1975, taught me driving and introduced me to American football, baseball, and broomball. Dan passed away recently, and 
we will miss him dearly.
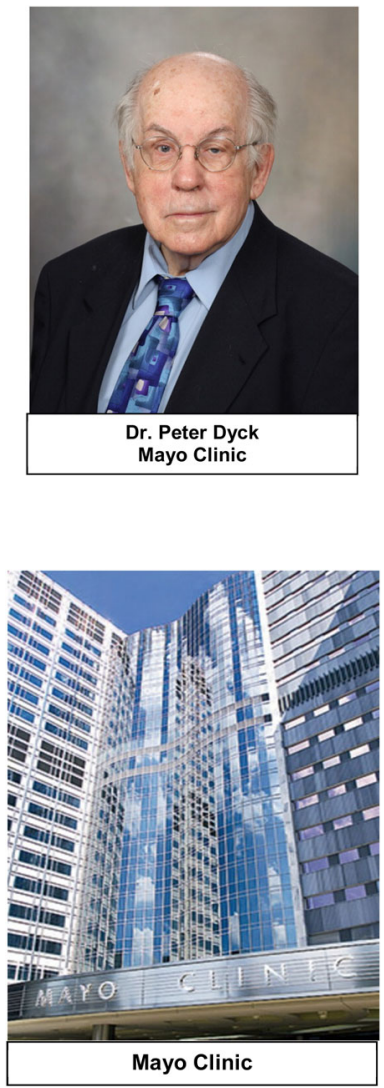

In 1977, I went back to India, got married to Lakshmi and had the pleasure of welcoming a daughter (Sowmya) and son (Ram) to the family. The Hormel lab was active and productive, and the environment was conducive for research keeping my stay at the Institute for almost 10 years. In addition to working on the ether lipids [4] I was involved in three projects related to lipids in spermatozoa [5], identification and characterization of a novel pathway involved in the generation of N-acyl- phosphatidylethanolamine (NAPE) in normal and ischemic heart and brain and it's conversion to $\mathrm{N}$-acylethanolamine (NAE) and phosphatidic acid (PA) by a novel NAPE-phospholipase D present in the myocardium and other tissues [6-10]. In the myocardium, we identified C16:0. C18:1 and C18:2 NAEs and missed the discovery of C20:4 NAE, which was named "Anandamide" (meaning Bliss) by another group. With Harald's support, I became part of the "Peripheral Neuropathy" Center headed by Dr. Peter Dyck, a world-renowned Neurologist at the Mayo Clinic in Rochester, MN. I was involved with Harald and Peter on a NINDS-funded Peripheral Neuropathy Center Grant investigating the role of inositol and inositol lipids in nerve conduction velocity and nerve function in diabetic peripheral neuropathy $[11,12]$. This was a challenging project, but it was fun to work with the neurologists at the Peripheral Neuropathy Center, my first experience working with clinicians on a human disease. My interaction with Peter, and others at the Peripheral Neuropathy Center was instrumental in landing a faculty position in the Department of Neurology at the Mayo Clinic in 1985.

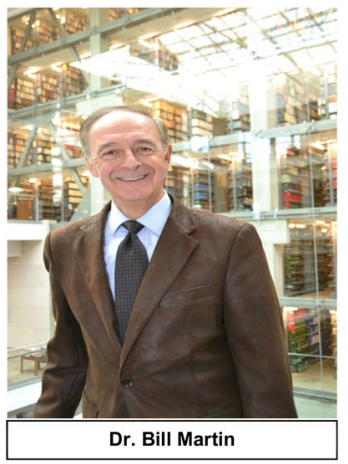

I had a short but memorable period in the Department of Neurology at Mayo Clinic. In 1985, Dr. Peter Dyck, the director of the Peripheral Neuropathy Center offered me the position of Associate Consultant and Assistant Professor of Biochemistry in the Department of Neurology, and I accepted the offer and we moved to Rochester, MN. I established my own lipid laboratory to investigate the inositol and inositol lipids in human peripheral neuropathy and rat model. It was exciting to be a part of the Mayo Clinic conducting cutting-edge basic and clinical research with the neurologists. At the same time, I also had the privilege to collaborate with Dr. Bill Martin, MD, who was a pulmonologist and researcher at the Mayo Clinic. Bill was then doing research on the Amiodarone-induced pulmonary toxicity. We then became active collaborators focusing on the amiodarone-induced changes in the lung lipid metabolism [13], which later led to secure NIH funding and successful publications of our scientific research. Getting to know Bill and establishing scientific collaboration with him at the Mayo Clinic turned out to be a very important milestone in my scientific and professional career in 1989. Unexpectedly, within 12 months of my tenure at the Mayo Clinic as a faculty member, I received an offer from the Unilever Research at Bombay as a scientist and manager of Lipton, India Cattle and Poultry Feeds. The offer was very attractive with a high salary and perks. After considerable deliberation with my wife, I decided to accept that position in 1986. Peter tried his best to persuade me to stay back at the Mayo Clinic and was disappointed to see me leave the department as he was instrumental in creating that position for me. This was a difficult decision, but our families were all in India and we thought it was the right decision to reunite with our families there. Before leaving Mayo Clinic, Peter and I had a long chat and I still remember Peter's words - "Nati, you belong here and I know for sure that you will be returning 
to USA in near future".

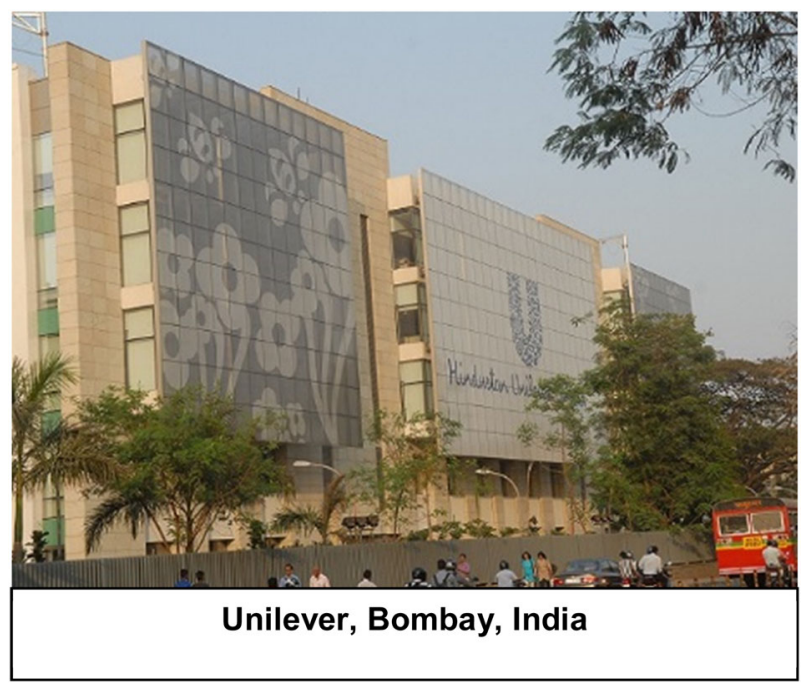

I started a new life and a different career at Unilever R \& D after returning to Bombay in June 1986 with my wife and two kids as a Manager and Research Scientist. Dr. Ashok Ganguli, a biochemist and Ph.D. from the University of Illinois, Urbana was the Chairman of the company and Dr. K.K.G. Menon, a biochemist, was the Director of the R \& D facility in Chakala, Andheri. I was assigned to manage the formulations of the cattle and poultry feeds for Lipton, India and allocated nearly $20 \%$ of my time to research on plant lipids. Managing the feeds was new and interesting and my research work on polyphosphoinositides in plants was my inspiration to get back to the laboratory. The manuscript that resulted from this research project describing for the first time the presence of polyphosphoinositides in the plant leaves was accepted in Biochim Biophys Acta Lipid Metabolism without revision [14]. Although the environment was good for research, it was not fully supported by the management whose focus was on the soaps and detergents that generated the company's profits. At one point, I was entrusted to develop feeds for the aquaculture of tiger prawns (shrimps) but white fish meal that was necessary to make the feed was not available then in India, and could not be imported from Denmark, I was asked to use the inferior quality fish meal from local market. Although my team successfully came up with a formulation and manufactured several tons of the prawn feed in a pilot extruder plant, the quality of the prawn feed was inferior because the local low-grade fish meal used as the starting material. Although I was well paid with great perks and was provided a rent-free threebed room flat in Chakala, Andheri R \& D campus, I badly missed scientific research and academic freedom. In addition, decisions were made by the administrative bureaucrats that were not based on the research output and scientific merit. These factors played a major factor in reconsideration of my continuation as a scientist at the Unilever, Bombay. Being heavily motivated and driven by scientific research, I decided to call it quits and return to USA with words from Dr. Dyck echoing in my ears that "I will come back to USA". As a result, Dr. Harald Schmid, my mentor at the Hormel Institute was supportive of my decision and magnanimous to invite me back to the institute as a Visiting Professor.

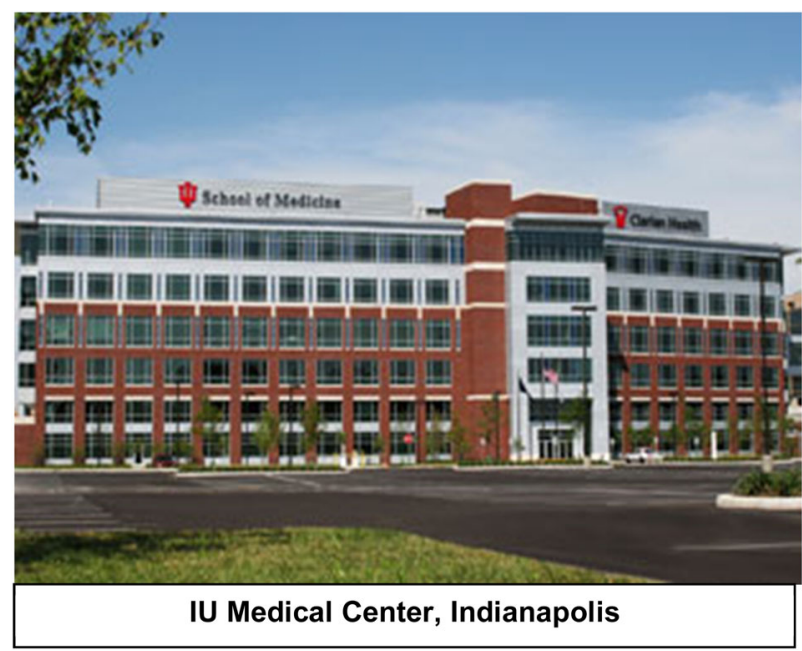

By Christmas 1988, my family and I were back in Austin, Minnesota. We were fortunate to have this opportunity and to get to know Dr. Parinandi (Pari), his wife Nagi and their kids. Pari was doing a post-doctoral fellowship with Harald and he was extremely helpful in making us home and rendering all the support to restart our lives. With Harald's help I got re-connected to Dr. Bill Martin, who had become the Chief of Pulmonary at Indiana University School of Medicine in 1988 and encouraged me to apply for a tenure track faculty position in the Pulmonary Division. I got recruited amidst tough competition and was extremely grateful to Bill for his support. The Chair of Medicine, Dr. Gus Watanabe, laid out a plan that I would need to get a R01 within the next 3-4 years for tenure and promotion. Interestingly, I shifted my research focus from neurology to vascular biology and pulmonary medicine, and this transition was facilitated by Bill and Dr. Garcia (Skip). Skip was also a new faculty in the division and a pulmonologist with expertise in the vascular endothelial biology and permeability. I learned most of the basic techniques from his laboratory and within a year, I was comfortable working with the lung vascular endothelial cell signaling and oxidative stress. Skip and I became good friends and started doing collaborative research that was mutually beneficial and resulted in many publications in endothelial biology, cellular signaling, and barrier regulation. 
Among the many papers, one published in the Am $J$ Respir Cell Mol Biology on sphingosine-mediated activation of phospholipase D (PLD) in endothelial cells was extremely significant as we were the first to demonstrate the potential of sphingosine and sphingolipids in vascular endothelial function. In subsequent years, we investigated how sphingosine-1-phosphate (S1P) derived from sphingosine served as a naturally occurring bioactive lipid that mediated cellular lipid signaling via five G-protein-coupled receptors, stimulating several cellular functions [15]. Special thanks to Matt Scribner and Dr. Suri Vepa for their contributions and hard work to my success [16-18]. I was awarded my first NIH grant in 1993, and I was tenured and promoted to full Professor by 1995 .

I must thank Dr. T.K. Li of the Endocrinology Division and Head of the Alcoholism Research Center, and Associate Dean of Research at Indiana University, who was extremely supportive of my research and funded the pilot project on PLD as a biomarker in alcoholism. The head of the Biochemistry Department, Dr. Bob Harris, also encouraged me to teach lipid biochemistry and participate in the Problem Based Learning curriculum for the Medical students. My interactions with Skip helped me and my group to conduct exciting work on S1P and its analogs in the vascular endothelial barrier regulation [19]. During this time, I trained clinical fellows and postdoctoral students, which was rewarding. In a short time of 8-9 years, with luck on my side and working with the right investigators, I was able to successfully switch my research from neurobiology to vascular biology and got funded by the NIH R01 grants to do research on the lipids in lung pathology. I am grateful to Bill, Skip, TK, Bob, and others who were instrumental in my success becoming an established vascular biologist. I also had the satisfaction of teaching and sharing my intellectual knowledge, technical know-how on lipids, and the role of lipids in lung disorders to my colleagues at the IU. My wife, Lucky, a graduate with English major, got trained to become an expert in isolation and culturing of the human umbilical vein endothelial cells and lung endothelial cells by Skip and his group, which she continued until her retirement. My tenure at the IU turned out to be a remarkable one, which carved out my and my family's destiny as we took a big risk of returning to USA without any promises and solid plans for re-establishment. I was very fortunate to be at the right place at the right time and had the right people to help me with the successful transition. I would never forget the moment when Bill stopped by my office with a cake to congratulate and celebrate my first R01 in 1993. I cherish the friendship and collaborations with Skip Garcia as a Project
Principal Investigator in the PPG that has been funded since 1998.
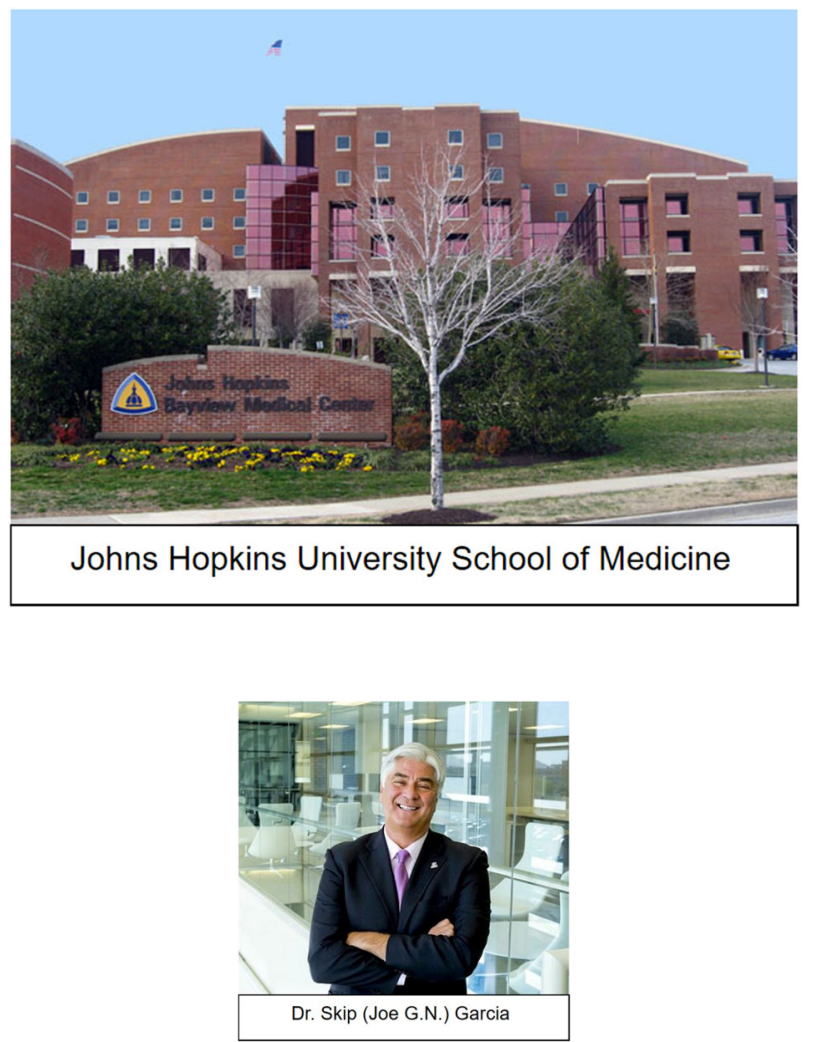

All good things must end, and in 1998, Skip accepted the position as the Chief of Pulmonary at the Johns Hopkins University School of Medicine and convinced us and others to move to Baltimore, MD. Although we were well settled at the IU, opportunities at Hopkins were exciting and tempting. Working at Johns Hopkins was memorable and remarkable-I was extremely fortunate to be at Johns Hopkins, a powerhouse for education, patient care, and research. The environment was conducive for collaborations, congeniality, and for great scientific research and success. The division under Skip's leadership was ranked \#2 or \#3 in the country and I had fantastic opportunity to work with excellent pulmonary fellows and clinical investigators in the areas of asthma, sepsis, COPD, and pulmonary hypertension. My laboratory was actively involved in bronchial epithelial and lung microvascular endothelial cell models to dissect out the role of lipid mediators in several lung pathologies. I had the good fortune to have exceedingly talented post-docs and pulmonary fellows in the lab to carry out cutting edge pulmonary research. Colleagues like Drs. Rhett Cummings, Narasimham Parinandi, Suri Vepa, Lixun Wang, Peter Usatyuk, Ashis Choudhary, Yutong Zhao, Evgeny Berdyshev, Bahman Saatian, Tonya Watkins, and Arjun Pennathur worked hard and were turning out several exceptional papers in excellent high 
priority and peer-reviewed journals [20-28]. Their untiring efforts in part contributed to my success. I had NIH funding to investigate ROS signaling in the lung pathologies, role of S1P/S1PRs in the endothelial function, and involvement of LPA/LPARs in the alveolar and bronchial epithelial biology. In addition to my collaboration with Skip, I started interacting with Dr. Steve Georas, an immunology and asthma expert in the Pulmonary Division at the Johns Hopkins School of Medicine. Soon, we discovered high levels of lysophosphatidic acid (LPA) in the BAL fluids of asthmatics compared to the normal subjects and Steve began investigating the role of LPA and autotaxin that generates LPA in the animal models of asthma [29]. I was overwhelmingly pleased to introduce another pulmonologist, Dr. Georas, to a novel paradigm, the role of lipid mediator(s) in lung diseases. Sharing my scholarly and technical expertise with my colleague-researcher with a different expertise gave me immense satisfaction and our collaboration directed our research to novel heights. Also, I had highly fruitful collaborations with Drs. Bill Spannhake, and John Samet of the Bloomberg School of Public Health at the Johns Hopkins University [30, 31]. Dr. Samet invited Skip and me to be part of his EPA multi-milliondollar grant to address the role of particulate matter (PM) in the human health and diseases. In addition, I came to know Drs. Nigel and Susan Pyne at Glasgow, Scotland and Dr. Bob Bittman at the CUNY, NY, who became great collaborators and good friends [32]. The environment at the Johns Hopkins fostered many wonderful collaborations, which were extremely productive all these years. Tenure at Johns Hopkins was phenomenal as I had great opportunities to experience diverse research activities and interact and collaborate with exceptional researchers with varied scientific backgrounds. The collegiality at Hopkins University was great, and unique.

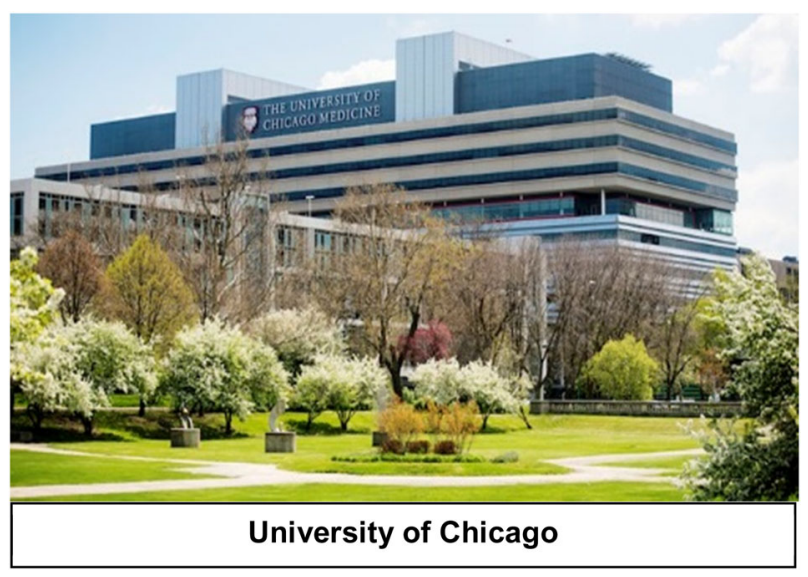

Skip, after seven years at Hopkins, decided to become the Chair of Medicine at the University of Chicago. Skip wanted the entire group to move to Chicago as part of the PPG, but my wife and I were not too enthusiastic of moving to Chicago. Skip persuaded us with wining and dining and finally we agreed. The move to Chicago happened in May 2005. Moving the lab to the University of Chicago (UoC) was much easier as this was the second move in 15 years. I had several former colleagues from Hopkins rehired at University of Chicago. Skip put in resources to start a Lipidomics facility with Dr. Berdyshev as the director. This facility was of immense help in quantifying bioactive lipids in biological samples using LC-LC/MS. I was able to set up new collaborations and one that turned out to be important was with Dr. Ravi Salgia of the Department of Hematology $\&$ Oncology. Dr. Salgia was working on Mesothelioma and lung cancer and we plugged in studies related to sphingolipids in the cancer models. Continuing my collaboration with Skip and his group, we identified several novel SNPS in SPHK1, SPHK2, SIPR1 PBMCs from sepsis patients. Furthermore, GWAS analysis of PBMCs from IPF patients revealed novel the SNPS in SGPL1 and LYCAT genes. The LYCAT gene in humans encodes for the protein, lysocardiolipin acyltransferase that modifies immature cardiolipin to mature cardiolipin in mitochondria. This was exciting, and my lab started translational work in a couple of lung pathologies such as the IPF and lung cancer [33-36]. Sphingolipids and their metabolizing enzymes were identified in several lung pathologies and with the help of Skip I put a PPG together. Several investigators were identified, a theme on "Sphingolipids in acute lung injury" was conceived, grant was written, submitted and got funded. This was a milestone in my career and help from Skip was crucial for the success.

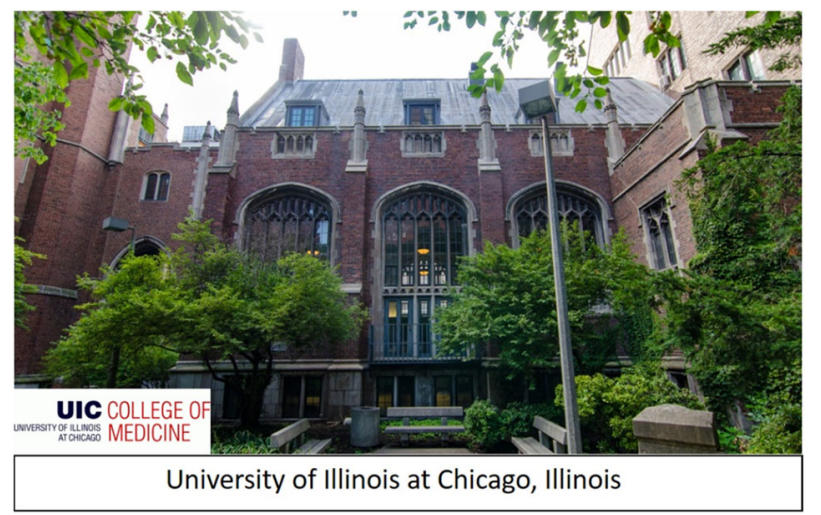

As part of the IPF study with Dr. Imry Nath and Skip, I got to know Dr. Andy Tager at Massachusetts General Hospital, who was doing pioneering work on LPA and autotaxin in IPF. Andy and I became good friends and published pioneering scientific papers together [37]. As part of the group working on sphingolipids, we initiated collaborations with Dr. Bob Bittman of the CUNY, NY, and Dr. Ralph Weishelbaum at the University of Chicago to 
interrogate the effects of radiation on lung sphingolipids. Bob at the CUNY provided us with the newly synthesized S1P analogs and inhibitors for SPHK1 and SPHK2, which were extremely useful in our investigations. During this time, collaborations with Drs. Nigel and Susan Pyne were progressing well with many publications and visits by Pynes to my laboratory. Our research efforts reached a new milestone at UoC with an emphasis on the OMICS in lung diseases. My tenure at the UoC was short, but the experience was great with wonderful colleagues in the Pulmonary Division and in the Division of Biological Sciences. Special thanks to Drs. Julian Solway, Steve White, Anne Sperling, Kostia Birukov, Evgeny Berdyshev, Ira Gorshkova, Imry Nath, Alan Leff, Russel Hall, Ravi Salgia and my colleagues in the lab for their support and collegiality.

While we were settling down at the UoC, another move became imminent as Skip was invited to become the ViceChancellor of Research at the University of Illinois at Chicago (UIC). I could have stayed back at UoC, but Skip's dynamism and friendship always influenced my decision to move along to the new adventurous pastures. Transferring the lab to the UIC was the easiest. Most of the PIs who moved from the Johns Hopkins to the UoC decided to make the switch. However, being governed by state rules and regulations, it took a much longer time to get all the approvals and paperwork in place for the labs to get started. Having been associated with the Department of Medicine/ Pulmonary Division for almost 20 years, I decided to opt for a dual appointment with the Departments of Pharmacology and Medicine at the UIC. The Institute for Respiratory Medicine was initiated and established with Skip as the Director and me as the co-director. Interactions with Skip and his group continued with the funding of the PPG on "Sphingolipids in Acute Lung Injury" with four projects and four cores over which I acted as the overall Program Director. I also initiated collaborative work with Drs. John Christman (Pulmonary), Steve Ackerman (Biochemistry), and Gye-Young Park (Pulmonary) on autotaxin (ATX)/ LPA signaling axis in the segmental allergen-challenged asthmatics and murine model of asthma. We published the novel findings in Am J Respir Critical Care Medi in 2013 [38]. We also forged forward with two new initiatives: one on pulmonary fibrosis and the second one on cardiolipin metabolism in lung cancer. Dr. Huang, a fellow in the lab, was able to demonstrate that SPHK1 to be a target in bleomycin-induced pulmonary fibrosis and this finding was extended to the asbestos model with Dr. David Kamp and his group at the Northwestern University School of Medicine [39-41]. Dr. Anantha Harijith, a neonatologist and a pediatrician, joined my laboratory in 2011 to do research in bronchopulmonary dysplasia (BPD). He started to investigate the role of S1P and S1P receptors in the development of BPD in neonatal mouse model and observed that genetic deletion of $S p h k 1$, but not $S p h k 2$, was protective from hyperoxia-induced lung inflammatory injury [42-46]. He was successful in getting grants including a R01 from $\mathrm{NIH}$ and then a USA/European patent approved for the use of SPHK1 inhibitor PF-543 in various lung pathologies including BPD. This was very exciting and rewarding with hope of doing phase $2 / 3$ clinical trials. The SPHK1 inhibitor, PF-543 showed protection in pulmonary fibrosis [39], and hypoxia/Sugen model of pulmonary artery hypertension [47-49].

I also had good fortune to collaborate with Dr. Roberto Machado at UIC. I was happy to induct Roberto to the field of Sphingolipids in pulmonary arterial hypertension (PAH). This turned out to be an exceptional and productive collaboration with many publications and a Multi PI R01 to understand mechanisms of SPHK1/S1P signaling in the development and progression of hypoxia-induced PAH in pre-clinical animal models. Roberto moved to Indiana University School of Medicine as Chief of Pulmonary in 2018 but our collaboration has become stronger with new and exciting research in PAH. I also have the immense satisfaction of introducing the field of lipids in lung diseases to another physician-scientist.

Dr. Panfeng Fu, a senior Research faculty in the lab, working in Pseudomonas aeruginosa infection model of mouse lung observed that $S p h k 2$, but not $S p h k 1$, deletion protected mice from lung inflammation and injury [50-52]. Subsequently, David Ebenezer, a graduate student showed that $P$. aeruginosa infection increased nuclear S1P generation mediated by translocation of SPHK2 to the nucleus and epigenetically regulated transcription of IL-6 via histone acetylation modulation by HDAC1/2. This exciting finding was published in Thorax and has relevance to cystic fibrosis as we were able to show nuclear localization of SPHK2 in alveolar and bronchial epithelial cells of CF lungs compared to controls [52].

The current working hypothesis is blocking SPHK2 in CF may reduce $P$. aeruginosa infection of the lung, a major problem associated with CF patients. In addition, our work has identified modulation of nuclear ROS generation by NOX4 after $P$. aeruginosa infection of alveolar epithelial cells, and this nuclear ROS oxidized HDAC $1 / 2$ to inhibit HDAC activity and regulate chromatin remodeling [53]. These studies have opened a new and novel role for nuclear S1P signaling in regulating chromatin remodeling and gene regulation. We have initiated work on the role of host sphingolipids on SARS-CoV2 infection of lung epithelium; however, this project will need additional resources to move forward. Dr. Bellur Prabhakar, Vice-Dean of Research, has helped out with cytotoxicity assay.

My experience at the UIC has been unique. I am probably doing some of the best translation work of clinical relevance to various lung pathologies. I was fortunate to 
train three excellent graduate students (Ms. Vidyani Suryadevara, Mr. David Ebenezer and Mr. Mark Shaaya), master's students from the Bio-engineering department, undergraduate students for lab experience, and high school students interested to learn about biological research. In addition, I was fortunate to have a hard-working colleague who were responsible for new ideas and implementation of the research in the lab. Special thanks to Drs. Panfeng Fu, Longshuang Huang, David Ebenezer, Vidyani Suryadevara, Mounica Bandela, Anantha Harijith, Prasanth Kumar, and Ramaswamy Ramchandran for their inputs, experimentation, and contributions to the publications. My successful research career was made possible by the hard work of all my students, post-docs, pulmonary fellows, trainees, and collaborators. Collaborations at the UIC with Drs. Tiruppathi Chinnaswamy, Dolly Mehta, Yuru Liu, Rich Minshal, Yulia Kumarova, Asrar Malik, Steve Dudek, Jeff Jacobson, Kamesh Bikkavilli, Weiguo Chen, Roberto Machado, Gye-Young Park, Steve Ackerman, Sekhar Reddy, Andrei Karginov, P.V. Subbaiah, Anantha Harijith, Bellur Prabhakar, and others are greatly valued and appreciated. Special thanks to Dr. Ramaswamy Ramchandran (Ram), who joined the lab in 2020 and he has been extremely helpful in managing the lab and to take a leading role in the project on the lamellipodin/lamellipodia in endothelial barrier regulation. Furthermore, his tireless efforts in putting the manuscripts together for submission during the last 18 months are greatly appreciated. I also wish to thank Dr. Prasad Kanteti for his contributions to my lab and research, valuable discussions, inputs, manuscript editing and being a very good friend.

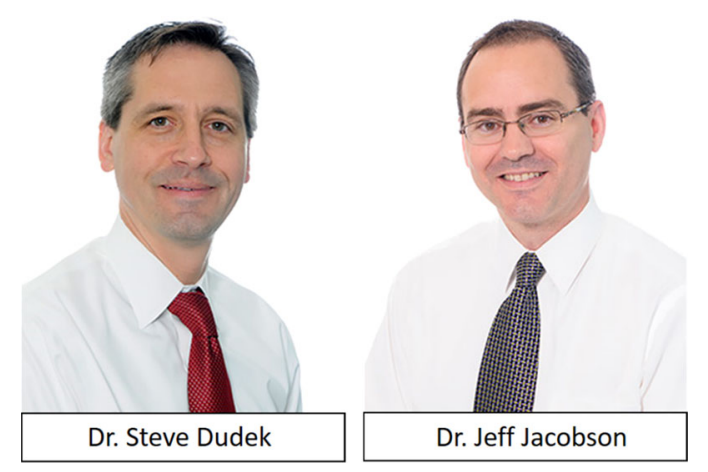

I wish to thank Dr. Asrar Malik, Head of Pharmacology for his support, encouragement and including me as project leader in one of his PPG. Special thanks acknowledging the support of Dr. Patricia Finn, Chair, Department of Medicine toward the endowed position of Earl M Bane Professor since 2013. It has been a pleasure to have known Drs. Dudek (Steve), and Jacobson (Jeff) for almost two decades. I knew them as pulmonary fellows at Hopkins and very rewarding and happy to see both them blossomed to successful physician-scientists with leadership roles at UIC. Steve is Professor and head of pulmonary division while Jeff is Professor and Associate chair of Medicine in the Department of Medicine at UIC. I cherish their friendship and collaborative interactions related to cytoskeletal regulation of endothelial barrier function $[54,55]$.

I am indebted to my parents, wife (Lakshmi), daughter (Sowmya), son (Dr. Venkatesan), son-in-law (Dr. Vijay Viswanathan) and my two grand-children (Sandhya and Keshav) for being part of my life and providing all the encouragement throughout my career. I extend special thanks to all my mentors for their guidance, training and inculcating scientific and professional ethics and integrity in my career. My research and standing in the scientific community would have been incomplete without my hard working colleagues from the lab, long-time collaborators and well-wishers, and all of my mentors.

The initiative and efforts of Drs. Parinandi, Zhao, and Pennathur in bringing out this special issue to honor my contributions to the field of lipid mediators in health and disease is touching and appreciated. The contributions by my mentors, collaborators, and leading researchers in lipids, and signaling highlight recent advances in the exciting field of lipid mediators in human health and disease. Even in my retirement, I hope our continued research builds off of what my collaborators and I have accomplished.

\section{Compliance with Ethical Standards}

Conflict of Interest The author declares no competing interests.

Publisher's note Springer Nature remains neutral with regard to jurisdictional claims in published maps and institutional affiliations.

\section{References}

1. Natarajan, V. \& Sastry, P. S. (1973). In vitro studies on the acylation 1-0-alkenyl glycero-3- phosphorylethanolamine by rat brain preparations. FEBS Letters, 32, 9-12.

2. Natarajan, V. \& Sastry, P. S. (1974). Enzymatic acylation of 1alkyl-, 1-alkenyl- and sn-glycero-3-phosphorylethanolamine in developing rat brain. Journal of Neurochemistry, 23, 187-192.

3. Natarajan, V. \& Sastry, P. S. (1975). Studies on the biosynthesis of ether-linked ethanolamine phospholipids in developing rat brain. Indian Journal of Biochemistry and Biophysics, 12, $340-350$

4. Natarajan, V. \& Schmid, H. H. O. (1978). Biosynthesis and utilization of long chain alcohols in rat brain. Aspects of chain length specificity. Archives of Biochemistry and Biophysics, 187, 215-222.

5. Selivonchick, D. P., Schmid, P. C., Natarajan, V. \& Schmid, H. H. O. (1980). Structure and metabolism of phospholipids in bovine epididymal spermatozoa. Biochimica et Biophysica Acta, 618, 242-254.

6. Epps, D. E., Natarajan, V., Schmid, P. C. \& Schmid, H. H. O. (1980). Accumulation of N-acylethanolamine glycerophospholipids 
in infarcted myocardium. Biochimica et Biophysica Acta, 618, 420-430.

7. Natarajan, V., Reddy, P. V., Schmid, P. C. \& Schmid, H. H. O. (1981). On the biosynthesis and metabolism of $\mathrm{N}$-acylethanolamine glycerophospholipids in infarcted dog heart. Biochimica et Biophysica Acta, 664, 445-448.

8. Natarajan, V., Reddy, P. V., Schmid, P. C. \& Schmid, H. H. O. (1982). N-Acylation of ethanolamine phospholipids in canine myocardium. Biochimica et Biophysica Acta, 712, 342-355.

9. Natarajan, V., Schmid, P. C., Reddy, P. V., Zuzarte-Augustin, M. L. \& Schmid, H. H. O. (1985). Occurrence of N-acylethanolamine phospholipids in fish brain and spinal cord. Biochimica et Biophysica Acta, 835, 426-433.

10. Schmid, H. H. O., Schmid, P. C. \& Natarajan, V. (1990). $\mathrm{N}$-acylated glycerophospholipids and their derivatives. Progress in Lipid Research, 29, 1-43.

11. Natarajan, V., Schmid, H. H. O. \& Sastry, P. S. (1984). Biosynthesis of long chain alcohols by developing and regenerating rat sciatic nerve. Journal of Neurochemistry, 43, 328-334.

12. Natarajan, V. \& Schmid, H. H. O. (1987). Inositol phospholipid hydrolysis by rat sciatic nerve phospholipase C. Journal of Neurochemistry, 49, 1878-1887.

13. Martin, W. J., Kachel, D. L., Vilen, T. \& Natarajan, V. (1989). Mechanism of phospholipidosis in amiodarone pulmonary toxicity. Journal of Pharmacology and Experimental Therapeutics, 251, 272-278.

14. Wagh, S. S., Menon, K. K. G. \& Natarajan, V. (1988). Evidence for the incorporation of $\left({ }^{32} \mathrm{P}\right)$ orthophosphate into leaf inositol phospholipids. Biochimica et Biophysica Acta, 962, 178-185.

15. Natarajan, V., Jayaram, H. N., Scribner, W. M. \& Garcia, J. G. N. (1994). Activation of endothelial cell phospholipase D by sphingosine and sphingosine-1-phosphate. American Journal of Respiratory Cell and Molecular Biology, 11, 221-229.

16. Natarajan, V., Suryanarayana, V., Verma, R. S. \& Scribner, W. M. (1996). Role of protein tyrosine phosphorylation in hydrogen peroxide-induced activation of endothelial cell phospholipase D. American Journal of Physiology, 271, L400-L408. (Lung Cell. Mol. Physiol. 15).

17. Vepa, S., Scribner, W. M. \& Natarajan, V. (1997). Activation of protein phosphorylation by oxidants in vascular endothelial cells. Free Radical Biology and Medicine, 22, 25-35.

18. Natarajan, V., Scribner, W. M. \& Vepa, S. (1997). Phosphatase inhibitors potentiate 4-hydroxynonenal-induced phospholipase D activation in vascular endothelial cells. American Journal of Respiratory Cell and Molecular Biology, 17, 251-259.

19. Garcia, J. G. N., Fenton, J. W. \& Natarajan, V. (1992).Thrombin stimulation of human endothelial cell phospholipase D activity. Regulation by protein kinase $\mathrm{C}$ and cyclic adenosine 3 '5' monophosphate.Blood, 79, 2056-2067.

20. Garcia, J. G. N., Verin, A. D., Schaphorst, K. L., Siddiqui, R., Patterson, C. E., Csortos, C. \& Natarajan, V. (1999). Regulation of endothelial cell myosin light chain kinase by Rho, cortactin and p60 ${ }^{\text {src }}$. American Journal of Physiology, 276, L989-L998.

21. Cummings, R., Parinandi, N. L., Zaiman, A., Garcia, J. G. N. \& Natarajan, V. (2002). Involvement of phospholipase D in sphingosine-1-phosphate induced interleukin-8 secretion in human bronchial epithelial cells. Journal of Biological Chemistry, 277, 30227-30235.

22. Wang, L., Cummings, R., Usatyuk, P., Morris, A., Irani, K. \& Natarajan, V. (2002). Role of phospholipase D-dependent-ERK activation in sphingophinc-1-phospholic induced IL-8 secretions in human bronchial epithelial cells. Biochemical Journal, 367, 751-760.

23. Parinandi, N. L., Usatyuk, P. V., Kleinberg, M. A., Pennathur, A., Zweier, J., Cummings, R., Cardounel, A. J., Garcia, J. G. N. \& Natarajan, V. (2003). Hyperoxia-induced NAD [P] H oxidase activation and regulation by MAP kinases in human lung endothelial cells. The American Journal of Physiology - Lung Cellular and Molecular Physiology, 284, L26-L38.

24. Usatyuk, P. V., Parinandi, N. L. \& Natarajan, V. (2004). Mitogen activated protein kinases regulates 4-Hydroxynonenal-induced actin rearrangement and endothelial barrier dysfunction. Journal of Biological Chemistry, 279, 11789-11797.

25. Cummings, R., Zhao, Y., Jacoby, D., Spannhake, W., Watkins, T., Ohba, M., Garcia, J. G. N. \& Natarajan, V. (2004).Protein kinase $\mathrm{C} \delta$ and NFKB mediate lysophosphatidic acid-induced IL8 secretion in human bronchial epithelial cells.Journal of Biological Chemistry,279, 41085-41094.

26. Saatian, B., Zhao, Y., He, D., Georas, S. N., Watkins, T., Spannhake, E. W. \& Natarajan, V. (2006). Roles of p38 MAP kinase and JNK in lysophosphatidic acid-induced IL-8 expression and secretion in human bronchial epithelial cells. Biochemical Journal, 393, 657-668.

27. Zhao, Y., He, D., Saatian, B., Watkins, T., Spannhake, E. W., Pyne, N. J. \& Natarajan, V. (2006). Regulation of lysophosphatidic acid-induced epidermal growth factor receptor transactivation and interleukin- 8 secretion in human bronchial epithelial cells by protein kinase $\mathrm{C} \delta$, Lyn kinase and matrix metalloproteinases. Journal of Biological Chemistry, 281, 19501-19511.

28. Petrache, I., Natarajan, V., Zhen, L., Medler, T. R., Richter, A., Cho, C., Hubbard, W. C., Berdyshev, E. V., \& Tuder, R. (2005). Ceramide upregulation causes pulmonary cell apoptosis and emphysema. Nature (Medicine), 11, 491-498.

29. Georas, S. N., Berdyshev, E., Hubbard, W., Gorshkova, I. A., Usatyuk, P. V., Saatian, B., Myers, A. C., Williams, M. A., Xiao, H., Liu, M. \& Natarajan, V. (2007). Lysophosphatidic acid is detectable in human bronchoalveolar lavage fluids at baseline and increased after segmental allergen challenge. Clinical and Exper Allergy, 37, 311-322.

30. Zhao, Y., He, D., Stern, R., Gorshkova, I. A., Solway, J., Spannhake, E. W., \& Natarajan, V. (2008). Transactivation of epidermal growth factor receptor regulates lysophosphatidic acidinduced cyclooxygenase-2 expression and prostaglandin E2 production through transcriptional factor, $\mathrm{C} / \mathrm{EBP} \beta$ in human bronchial epithelial cells. Biochemical Journal, 412, 153-162.

31. Zhao, Y., Usatyuk, P. V., Gorshkova, I., He, D., Wang, T., Moreno-Vinasco, L., Geyh, A. S., Breysse, P. N., Samet, J., Spannhake, E. W., Garcia, J. G. N. \& Natarajan, V. (2008). Regulation of COX-2 expression and IL- 6 release by particulate matter in airway epithelial cells. American Journal of Respiratory Cell and Molecular Biology, 40, 19-30.

32. Loveridge, C., Tonelli, F., Leclercq, T., Lim, K. G., Long, J. S., Berdyshev, E., Natarajan, V., Pitson, S. M., Pyne, N. J. \& Pyne, S. (2010). The Sphingosine kinase 1 Inhibitor 2-(p-hydroxyanilino)4-(p-chlorophenyl) thiazole induces proteosomal degradation of sphingosine kinase 1 in mammalian cells. Journal of Biological Chemistry., 285, 38841-38852.

33. Natarajan, V., Dudek, S., Jacobson, J. J., Weischelbaum, R. R., Bittman, R., Berdyshev, E. \& Garcia, J. G. N. (2013). Sphingosine-1-phosphate, FTY720, sphingosine-1-phosphate receptors in the pathobiology of acute lung injury. American Journal of Respiratory Cell and Molecular Biology, 49, 6-17.

34. Huang, L., Mathew, B., Zhao, Y., Ma, S.-F., Noth, I., Reddy, S. P., Harijith, A., Naftali, K., Zhou, T., Zhang, W., Garcia, J. G. N. \& Natarajan, V. (2014). Lysocardiolipin acyltransferase (LYCAT) is a novel target in human and murine pulmonary fibrosis. American Journal of Respiratory and Critical Care Medicine, $189,1402-1415$.

35. Huang, L. S., Jiang, P., Feghali-Bostwick, C., Reddy, S. P., Garcia, J. G. N. \& Natarajan, V. (2017).Lysocardiolipin acyltransferase regulates TGF- $\beta$ mediated lung fibroblast differentiation.Free Radical Biology Medicine,112, 162-173. 
36. Huang, L. S., Kotha, S. R., Avasarala, S., VanScoyk, M., Winn, R. A., Pennathur, A., Yashaswini, P. S., Salgia, R., Tyurina, Y. Y., Kagan, V. E., Zhu, X., Reddy, S. P., Bikkavilli, R. K. \& Natarajan, V. (2020). Lysocardiolipin acyltransferase regulates NSCLC cell proliferation and migration via the modulation of mitochondrial dynamics. Journal of Biological Chemistry, 295, 13393-13406.

37. Black, K. E., Bain, G., Berdyshev, E., Castelino, F. V., Shea, B. S., Probst, C. K., Fontaine, B., Bronova, I., Goulet, L., Lagares, D., Ahluwalia, N., Knipe, R. S., Natarajan, V. \& Tager, A. M. (2016). Autotaxin activity increases following lung injury, but is not required for LPA production in the lung or for pulmonary fibrosis. The FASEB Journal, 30, 2435-2450.

38. Park, G. Y., Lee, Y. G., Berdyshev, E. V., Fu, P., Gorshkova, I., Li, Y., Chung, S., Karpurapu, M., Deng, J., Rajan, R., Nyenhuis, S., Kelly, E. A. B., Jarjour, N. N., Morris, A. J., Smyth, S. S., Pretwich, G., Aidinis, V., Chun, J., Ackerman, S. J., Natarajan, V. \& Christman, J. W. (2013). Autotaxin production of Lysophosphatidic acid mediates allergic asthmatic inflammation. American Journal of Respiratory and Critical Care Medicine, 188, 928-940.

39. Huang, L. S., Sudhadevi, T., Fu, P., Punathil-Kannan, P. K., Ebenezer, D. L., Ramchandran, R., Putherickal, V., Cherish, P., Zhou, G., Ha, A. W., Harijith, A., Kamp, D. W., \& Natarajan, V. (2020). Sphingosine kinase 1/S1P signaling contributes to pulmonary fibrosis by activating Hippo/YAP pathway and mitochondrial reactive oxygen species generation in lung fibroblasts. International Journal of Molecular Sciences, 21(6), 2064.

40. Suryadevara, V., Huang, L. S., Kim, S.-J., Cheresh, P., Shaaya, M., Bandela, M., Fu, P., Feghali-Bostwick, C., Di Paolo, G., Kamp, D. W., \& Natarajan, V. (2019). Role of phospholipase D in bleomycin-induced mitochondrial reactive oxygen species generation, mitochondrial DNA damage, and pulmonary fibrosis. Am J Physiol Lung Cell Mol Physiol, 317, L175-L187.

41. Cheresh, P., Kim, S.-J., Hunag, L. S., Watanabe, S., Joshi, N., Williams, K. J. N., Chi, M., Lu, Z., Harijith, A., Yeldani, A., Lam, A. P., Gottardi, C., Misharin, A. V., Budinger, S. G. R., Natarajan, V. \& Kamp, D. W. (2020). The sphingosine kinase 1 inhibitor, PF543, mitigates pulmonary fibrosis by reducing lung epithelial cell mtDNA damage and recruitment of fibrogenic monocytes. International J Molecular Sciences, 21(16), 5595. Published online 2020 August 5th https://doi.org/10.3390/ijms21165595.

42. Harijith, A., Pendyala, S., Reddy, N. M., Bai, T., Usatyuk, P. V., Berdyshev, E. V., Gorshkova, I., Huang, L. S., Mohan, V., Garzon, S., Kanteti, P., Reddy, S. P., Raj, U., \& Natarajan, V. (2013). Sphingosine Kinase 1 is required for hyperoxia-induced bronchopulmonary dysplasia in a murine model: role of S1P and NOX proteins. American Journal of Pathology, 183, 1169-1182.

43. Harijith, A., Ebenezer, D. L., \& Natarajan, V. (2014). Reactive oxygen species at the crossroads if inflammasome and inflammation. Frontiers in Physiology, 5, 352 https://doi.org/10.3389/ fphys.2014.00352. eCollection207.

44. Harijith, A., Natarajan, V., \& Fu, P. (2017). The role of nictotinamide adenine dinucleotide phosphate oxidases in lung architecture remodeling. Antioxidants, 6, $104 \mathrm{https} / / /$ doi.org/10.3390/a ntiox6040104.

45. Ha, A., Sudhadevi, T., Ebenezer, D. L., Fu, P., Berdyshev, E., Ackerman, S., Natarajan, V. \& Harijith, A. (2020). Neonatal therapy with PF543, a Sphingosine kinase 1 inhibitor, suppresses hyperoxia-induced airway remodeling and hyper reactivity in a murine model of bronchopulmonary dysplasia. Am J Physiol Lung Cell Mol Physiol, 319, L497-L512.
46. Ha, A., Bai, T., Ebenezer, D.L., Sethi, T., Sudhadevi, T., Mangio, L. A., Garzon, S., Pryhuber, G., Natarajan, V., \& Harijith, A. Sphingosine kinase 1 regulates lysysl oxidase through STAT3 in hyperoxia-mediated neonatal lung injury. Thorax, In Press, 2021.

47. Chen, J., Tang, H., Sysol, J. R., Moreno-Vinasco, L., ShiouraB, K. M., Chen, T., Gorshkova, I., Wang, L., Huang, L., Sammani, S., Zhou, G., Raj, J. U., Garcia, J. G. N., Berdyshev, E., Jason, X.J., Natarajan, V., \& Machado, R. F. (2014). The sphingosine kinase $1 /$ sphingosine-1-phosphate pathway is up-regulated in pulmonary arterial hypertension and promotes pulmonary vascular remodeling. American J Respiratory and Critical Care Medicine, 190, 1031-1043.

48. Sysol, J. R., Natarajan, V. \& Machado, R. F. (2016). PDGF induces SphK1 expression via EGgr-1 to promote pulmonary artery smooth muscle cell proliferation. The American Journal of Physiology: Cell Physiology, 310, C983-C992.

49. Sysol, J. R., Chen, J., Singla, S., Comhar, S., Erzurum, S. C., Natarajan, V. \& Machado, R. F. (2018). MicroRNA-1 is decreased by hypoxia and contributes to the development of pulmonary vascular remodeling via regulation of sphingosine kinase 1. The American Journal of Physiology: Cell Physiology, 314, L461-L462.

50. Fu, P., Usatyuk, P. V., Anne, C., Jacobson, Jr, J., Garcia, J. G. N., \& Natarajan, V. (2015). Role of paxillin and paxillin tyrosine phosphorylation in HGF/S1P mediated ROS generation, lamellipodia formation and endothelial barrier function. Pulmonary Circulation, 5, 619-630.

51. Fu, P., Ebenezer, D. L., HA, D. L., Suryadevara, V., Harijith, A., \& Natarajan, V. (2018). Nuclear lipid mediators: Role of nuclear sphingolipids and sphingosine-1-phosphate signaling in epigenetic regulation of Inflammation and gene expression. Journal of Cellular Biochemistry, 119, 6337-6353.

52. Ebenezer, D.L., Berdyshev, E., Bronova, I.A., Tiruppathi, C., Kumarova, Y., Benevolenskaya E.V., Suryadevara, V., Ha, A.W., Harijith, A., Tuder, R. M., Natarajan, V., \& Fu, P. Pseudomonas aeruginosa stimulates nuclear sphingosine-1-phosphate generation and epigenetic regulation of lung inflammatory injury. Thorax. 2019 Feb. pii: thoraxjnl-2018-212378. https://doi.org/10. 1136/thoraxjnl-2018-212378.

53. Fu, P., Ramchandran, R., Sudhdevi, T., Kumar, Prasanth, P. K., Krishnan, Y., Liu, Y., Zhao, Y., Parinandi, N. L., Harijith, A., Sadoshima, J., \& Natarajan, V. (2021). NOX4 mediates Pseudomonas aeruginosa-induced nuclear reactive oxygen species generation and chromatin remodeling in lung epithelium. Antioxidants, 10(3), 477 https://doi.org/10.3390/antiox10030477. In Press.

54. Mathew, B., Jacobson, J. R., Berdyshev, E. V., Huang, Y., Sun, X., Zhao, Y., Gerhold, L. M., Siegler, J., Evanovski, C., Wang, T., Zhou, T., Zaidi, R., Moreno-Vinasco, L., Bittman, R., Chen, C. T., LaRiviere, P. J., Lussier, Y. A., Dudek, S. M., Natarajan, V., Weichselbaum, R. R. \& Garcia, J. G. N. (2011). Critical role of sphingolipid pathway components in murine radiation-induced lung injury. protection by sphingosine 1-phosphate analogues. The FASEB Journal, 25, 3388-3400.

55. Mathew, B., Jacobson, J. R., Siegler, J. H., Moitra, J., Blasco, M., Xie, L. S., Unzueta, C., Zhou, T., Evenoski, C., Al-Sakka, M., Sharma, R., Huey, B., Bulent, A., Smith, B., Sundararajan, J., Reddy, N. M., Reddy, S. P., Dudek, S. M., Natarajan, V., Weichselbaum, R. R. \& Garcia, J. G. N. (2013). Role of MIF in age-related susceptibility to radiation lung injury via $\mathrm{Nrf} 2$ and antioxidant regulation. American Journal of Respiratory Cell and Molecular Biology, 49, 269-278. 